\title{
NABUCO E O BRASIL ENTRE EUROPA, ESTADOS UNIDOS E AMÉRICA LATINA
}

\author{
LESLIE BETHELL
}

\section{RESUMO}

Até o começo do século XX, quando Joaquim Nabuco (1849-1910) refletia sobre as relações do Brasil com o restante do mundo, ele pensava principalmente na Europa. Durante a ultima década de sua vida, Nabuco tornou-se um defensor de uma aproximação com os Estados Unidos e um admirador da civilização norte-americana. A visão dele da América Espanhola/América Latina permeneceu em grande medida negativa. $\mathrm{O}$ artigo explora as transformações das relações internacionais do Brasil imperial ao Brasil republicano e o pensamento de Nabuco sobre as relações do Brasil com a Europa, a América Latina e os Estados Unidos.

PALAVRAS-CHAVE: Joaquim Nabuco; relações exteriores; Brasil; EUA,

Europa, América Latina.

\section{ABSTRACT}

Until the beginning of the zoth century, when Joaquim Nabuco (1849-1910) reflected on Brazil's relations with the rest of the world he thought primarily about Europe. During the last decade of his life he became a defender of closer relations with the United States and an admirer of North American civilization. His view of Latin America/Spanish America remained generally negative. The article explores the changes in Brazil's foreign relations from Empire to First Republic and Nabuco's thinking on Brazil between Europe, Latin America and the United States.

KEYWORDS: Joaquim Nabuco; foreign relations; Brazil; USA, Europe, Latin America.

Quando refletia sobre as relações do Império brasileiro com o restante do mundo, o jovem Joaquim Nabuco — nascido em Pernambuco em 1849, filho do senhor de engenho e senador José Thomaz Nabuco de Araújo, e formado nas Faculdades de Direito de São Paulo e Recife, no final da década de 1860 - pensava, como a maioria dos brasileiros ilustrados de sua geração e formação, sobretudo na Europa: os laços históricos, linguísticos e culturais do Brasil com Portugal; a influência da França na arte, arquitetura e literatura brasileiras, e, acima de tudo, a dependência comercial e financeira do Brasil em relação à Grã-Bretanha. 
Nabuco escreveu seu primeiro livro em português (Camões e os Lusíadas, 1872), mas também escreveu em francês, que era quase uma segunda língua (por exemplo, Le droit du meurtre, 1872, eL'amouret Dieu, 1874, um livro de poemas). Sua primeira viagem ao exterior - que se estendeu por doze meses entre 1873 e 1874, quando tinha 24 anos de idade - foi à Europa. A viagem consistiu principalmente num giro cultural à França e à Itália, mas incluiu um mês, entre junho e julho de 1874, na Inglaterra, quando falou inglês pela primeira vez. Embora tenha afirmado que Paris "foi eé a paixão cosmopolita dominante em redor de nós", ele escreveu em Minha formação (1900) que "a grande impressão que recebi não foi Paris, foi Londres". Nabuco ficou fascinado e encantado com a cidade, centro do poder econômico e político global, a metrópole imperial, a cidade universal. Ele admitiu ter sido "tocado por um começo de anglomania".

Em abril de 1876, aos 26 anos, Nabuco foi nomeado attaché à legação brasileira em Washington, iniciando então a carreira diplomática. Passou um ano nos Estados Unidos, que fora a primeira república a reconhecer, em 1824, a independência do Império brasileiro e com a qual o Brasil mantinha, em geral, relações amigáveis, ainda que distantes. Nada indica que ele considerava os Estados Unidos pós-Guerra Civil um país particularmente interessante. Reconhecia a contribuição que este país vinha dando ao progresso material, mas não, ainda, julgava ele, à cultura e à civilização. Comparava desfavoravelmente a república norte-americana à monarquia constitucional inglesa, e acreditava sinceramente que a Inglaterra era mais democrática do que os Estados Unidos. Ele havia lido, evidentemente, a obra de Walter Bagehot, The English Constitution (à qual dedicou um capítulo inteiro em Minha formação), e foi por ela fortemente influenciado, mas ainda não lera Democracia na América, de Alexis de Tocqueville.

Diferentemente do imperador D. Pedro II - que visitara os Estados Unidos por ocasião da Exposição do Centenário da Independência, em 1876, e passara quatro meses viajando pelo país, demonstrando um grande interesse pela indústria, meios de transporte, ciência e engenharia, agricultura, educação, prisões etc. Nabuco só saiu de Nova York e Washington para visitar Niagara Falls. Nesse período, ele concluiu L'option, um drama em francês, em versos, sobre a disputa franco-germânica da Alsácia. Quando, para seu grande prazer, foi transferido para a legação brasileira em Londres em outubro de 1877, confessou que lamentava não ter aproveitado melhor o tempo que passara nos Estados Unidos: "Eu cometi um grande erro vindo a este país, em vez de estudá-lo, de visitar suas instituições de caridade e de letras, de conhecer os seus homens. Quis divertir-me com as mulheres; o resultado é uma impressão de tempo perdido" ${ }^{2}$.
[1] Nabuco, Joaquim. Minha formação [1900]. Rio de Janeiro:Topbooks, 1999, pp. 64, 97, 99 e 103.

[2] Idem. Diários. Org. Evaldo Cabral de Mello. Rio de Janeiro/Recife: Bem-Te-Vi/Massangana, 2005 (Vol. I:1873-1888; Vol.II:1889-1910), vol.I, p. $220: 27$ set. 1877 . 
[3] Ibidem, vol. I, p. 183: 7 jul. 1877 . Sobre o conceito de "América Latina", as relações do Brasil com a América Latina/América Espanhola e as atitudes brasileiras para com a América Latina/América Espanhola durante os séculos XIX e XX, ver Bethell, Leslie. "O Brasil e a ideia de América Latina em perspectiva histórica". Estudos Históricos, $\mathrm{n}^{\circ} 44,2009$, pp. 289-321.

[4] Nabuco, Minha formação, op. cit., p. 177 .
Como a maioria dos escritores e intelectuais brasileiros, Nabuco não se identificava com a outra América, a América Espanhola ou América Latina, como era chamada cada vez com maior frequência. O Brasil e a América Espanhola/América Latina têm em comum a herança ibérica e católica, mas diferenças importantes os separam: a geografia, a história, a cultura, acima de tudo a língua - e, no século XIX, as instituições políticas. Após a instabilidade dos anos de 1830 , o Brasil monárquico encontrava-se politicamente estável e "civilizado", ao contrário das repúblicas hispano-americanas, que os brasileiros consideravam extremamente instáveis, violentas e "bárbaras". As relações entre o Império brasileiro e as repúblicas hispano-americanas eram muito limitadas - com, evidentemente, uma exceção: o Rio da Prata, onde o Brasil travou três guerras. Além disso, o Brasil não se identificava com os inúmeros projetos dos países vizinhos para uma união interamericana. O diário de Nabuco contém poucas referências à América Espanhola durante o ano que passou nos Estados Unidos. Ele comenta a expansão territorial dos Estados Unidos às expensas do México ("O México pertence aos Estados Unidos") e descreve o restante dos países como "um mosaico de fraude, de anarquia, de militarismo e de revolução"3.

Nabuco permaneceu em Londres como attaché à legação brasileira por menos de seis meses, retornando ao Brasil em abril de 1878 devido à morte do pai. E como seu pai pretendia, e mesmo planejara, Nabuco começou então sua carreira política disputando, e vencendo, uma eleição em Pernambuco em setembro do mesmo ano. Assumiu sua cadeira na Câmara dos Deputados em janeiro de 1879, aos 29 anos, "inteiramente sob a influência do liberalismo inglês, como se militasse às ordens de Gladstone [...] um liberal inglês - com afinidades radicais, mas com adherências whigs - no Parlamento brasileiro" 4. Inspirado por sua própria experiência pessoal em relação à escravidão quando era criança em Pernambuco, por diversas leituras do romance $A$ cabana do pai Tomás, de Harrier Beecher Stowe, e pelo exemplo dos abolicionistas ingleses e norte-americanos, sobretudo o inglês William Wilberforce, dedicou boa parte dos dez anos seguintes à campanha parlamentar pela abolição da escravidão no Brasil.

Desde o princípio, Nabuco reconheceu a importância de mobilizar a opinião pública internacional em favor de sua luta contra a escravidão no Brasil com base na crença de que os escravocratas não poderiam resistir à pressão do mundo civilizado. Em dezembro de 1880 , aproveitando o recesso parlamentar, viajou para a Europa a fim de chamar pessoalmente a atenção da comunidade internacional para a persistência da escravidão no Brasil. Em Lisboa, foi recebido na Câmara dos Deputados como líder do "partido" abolicionista do Parlamento brasileiro. Em Madri, foi homenageado pela Sociedad Abolicionista 
Española. Porém, o principal objetivo da viagem era estabelecer um contato pessoal com a British and Foreign Anti-Slavery Society, sediada em Londres, o que ocorreu em março de 1881. Fundada em 1839 após a emancipação dos escravos no Império Britânico, precisamente para promover a abolição da escravidão no mundo inteiro, a sociedade era, de longe, a mais importante e mais influente organização abolicionista em todo o mundo, e Nabuco acreditava que sua cooperação era essencial para o sucesso da luta antiescravidão no Brasil5.

Imediatamente após sua derrota nas eleições em outubro de 1881, Nabuco voltou a Londres. Durante uma estada de quase dois anos e meio, de dezembro de 1881 até abril de 1884, Nabuco dedicou grande parte de seu tempo a promover a causa abolicionista. Fez pesquisas no British Museum para seu livro O abolicionismo, publicado em Londres em agosto de 1883, e, sobretudo, colaborou ativamente com a Anti-Slavery Society. Junto com Charles Allen, secretário da sociedade, montou um eficiente esquema de propaganda antiescravista. Fornecia informações a Allen, que se encarregava de divulgá-las na imprensa, principalmente no jornal The Times de Londres, que Nabuco chamava de "a voz da civilização". O Times adotou uma clara postura em favor da abolição no Brasil, e era o meio ideal de divulgação, devido à enorme influência dentro e fora da Grã-Bretanha, não menos no próprio Brasil. Nabuco foi frequentemente criticado pelos escravocratas brasileiros por sua falta de patriotismo ao expor os males da escravidão no Brasil no exterior e encorajar a interferência europeia nos assuntos internos do país. Nabuco sempre sustentou que o verdadeiro patriotismo consistia em elevar o Brasil, independentemente dos meios, ao nível do mundo civilizado.

Ao retornar ao Rio de Janeiro em abril de 1884, Nabuco retomou a luta antiescravidão no Brasil. Porém, depois de sofrer duas derrotas eleitorais desapontadoras em Recife, seus pensamentos mais uma vez voltaram-se para Londres. Ele passou cinco meses na capital inglesa em 1887, trabalhando mais uma vez com seus amigos da Anti-Slavery Society, antes de sua eleição para a Câmara dos Deputados em setembro $^{6}$. E Nabuco fez mais uma viagem à Europa em apoio à causa abolicionista, dessa vez a Londres e a Roma, onde, em fevereiro, logrou assegurar o apoio do Papa Leão XIII, antes de a escravidão ter sido finalmente abolida em maio de 1888 .

A queda do Império em novembro de 1889 representou um final abrupto à carreira política de Joaquim Nabuco, monarquista dedicado, quando ainda não tinha completado 40 anos. Menos de um ano depois ele estava de volta a Londres, lá permanecendo por nove meses (de setembro de 1890 a julho de 1891), e mais quatro meses em 1892. Foi em Londres, em maio deste ano, na igreja jesuíta em Farm Streete no oratório Brompton, que Nabuco redescobriu sua fécatólica.À parte
[5] A Grã-Bretanha já havia desempenhado um papel crucial ao obrigar o Brasil a abolir o comércio transatlântico de escravos através do infame bill Aberdeen, de 1845, e da ação da Marinha britânica contra os navios negreiros emáguas territoriais brasileiras, em 1850 . Em um texto escrito quando era aluno da Faculdade de Direito, em Recife, datado de 1870, Nabuco afirmou: "a aplicação do bill Aberdeen é um ultraje a nossa dignidade de povo independente". Mas "a vergonha é nossa", porque o Brasil confiou à Inglaterra "o papel de defensor da humanidade". "A escravidão" (1870), com 230 páginas manuscritas, foi doado ao Instituto Histórico e Geográfico Brasileiro pela viúva de Nabuco, Evelina, em 1924. O texto foi publicado pela primeira vez na Revista do Instituto Histórico e Geográfio Brasileiro, em 1949.

\footnotetext{
[6] Sobre as relações de Nabuco com os abolicionistas britânicos, ver $\mathrm{Be}$ thell, Leslie e Carvalho, José Murilo de. Joaquim Nabuco e os abolicionistas britânicos. Correspondência 1880-1905 Rio de Janeiro: Topbooks/Academia Brasileira de Letras, 2008; Rocha, Antônio Penalves. Abolicionistas brasileiros e ingleses: a coligação entre Joaquim Nabuco e a British and Foreign Anti-Slavery Society (1880-1902). São Paulo: Editora da Unesp, 2008.
} 
seu ostracismo político, ele começava a se preocupar com sua saúde e a considerar a possibilidade de ficar permanentemente na Europa, antes de finalmente se estabelecer no Rio de Janeiro, onde dedicou os seis anos seguintes ao jornalismo e à pesquisa, escrevendo uma grande biografia de seu pai - Um estadista do Império (três volumes, 1897-1898) - eMinha formação (1900).

A proclamação da República em novembro de 1889 acarretou algumas mudanças importantes à política externa brasileira. O Manifesto Republicano de 1870 começava com a conhecida frase: "Somos da América e queremos ser americanos". Para os republicanos, o Brasil, sob o Império, era, infelizmente, "um país isolado", separado da América Espanhola/América Latina e dos Estados Unidos não só pela geografia, história, língua e cultura, mas também pela forma de governo. Os primeiros governos da República não demonstraram interesse muito maior pelas nações de língua espanhola do que o Império, com uma importante diferença:eles foram bem-sucedidos em todas as disputas de fronteira com seus vizinhos na América do Sul. No entanto, sob a República o país aproximou-se muito dos Estados Unidos e se tornou um árduo defensor do pan-americanismo.

A primeira Conferência Internacional de Estados Americanos (mais conhecida como Conferências Pan-Americanas) foi realizada em Washington, em outubro de 1889. Patrocinada pelos Estados Unidos, seu objetivo era estabelecer a liderança norte-americana no Hemisfério Ocidental, promover seu comércio e seus investimentos na região, e criar estruturas políticas mais ordenadas e previsíveis nos países ao sul. O Brasil foi a única não república convidada. Quando a República foi proclamada, logo após a abertura da Conferência, o senador Lafaiete Rodrigues Pereira foi imediatamente substituído na chefia da delegação brasileira por Salvador de Mendonça, um destacado republicano, cônsul-geral do Brasil em Nova York desde 1876. Ele foi orientado a seguir o "espírito americano". A Conferência Pan-Americana de Washington (1889-1890) e o período em que Salvador de Mendonça serviu como representante brasileiro na capital norte-americana (1890-1898) marcam o início da "americanização" da política externa brasileira na Primeira República.

Nabuco reconhecia que, com a implantação da República, o Brasil fazia agora parte de "um sistema político mais vasto [...] na América [...] [e era] obrigado a estudar a marcha do Continente [...] a pulsação

[7] Nabuco. Balmaceda [1895]. Org. José Almino de Alencar. São Paulo: Cosac Naify, 2008, p. 218. continental [...] nosso continente"7. Mas ele - que realizara suas primeiras viagens à América Espanhola em 1889 (a Montevidéu, Buenos Aires, Corrientes, Santa Fée Assunção em junho-agosto, em sua lua de 
mel, e a Montevidéu, Buenos Aires e Mendoza em novembro-dezembro) - revelava sua visão bastante negativa dos vizinhos do Brasil da América Espanhola por meio do descontentamento que expressava pelo novo sistema de governo do Brasil.

Estamos sob um governo verdadeiramente paraguaio... Nunca eupensei ver o Brasil rebaixado a um Paraguai, Uruguai, Equador, Argentina ou o que quiserem (jun.1890).

Estamos no redemoinho republicano da América. Somos um cadávergirando no sorvedouro da anarquia, vendo o Brasil tornar-se uma Venezuela, um México, uma Argentina, um Chile... propriedade do déspota do dia... (fev.1891).

Como o Brasilse sul-americanizou depressa, e com que fúria! [...] Como isto é sul-americano, como se vê a degradação típica deste infeliz hemisfério - ao lado do despotismo bestial, o republicanismo imbecil do paraguaio! (out.1893) $)^{8}$.

Por outro lado, Nabuco sempreviu o Chile, "ainda que de raça espanhola", como "um capricho de ordem moral na formação de América do Sul". O Império do Brasil e a república parlamentar do Chile foram os únicos que conseguiram evitar "o gênio sul-americano da ditadura". Contudo, isso mudou com a eleição de Balmaceda no Chile em 1886 e a derrubada de D. Pedro II em 1889 . No postscriptum ao seu livro Balmaceda (1895), um estudo sobre o "ditador" chileno, Nabuco descreve a América Latina (incluindo agora o Brasil) como "um vasto continente em estado permanente de desgoverno, de anarquia" 9 .

O amigo e companheiro monarquista, Eduardo Prado, era igualmente hostil às repúblicas hispano-americanas, das quais o Brasil estava separado pela "diversidade da origem e da língua". "Nem o Brasil físico, nem o Brasil moral formam um sistema com aquelas nações", escreveu Prado em A ilusão americana (1893; 2 ed., Paris, 1895). Mas ele também condena a conquista territorial e a exploração econômica da América Espanhola pelos Estados Unidos, sua diplomacia arrogante e o uso da força militar. Quanto ao pan-americanismo, "afraternidadeamericanaéuma mentira". Em seu diário, Nabuco confessou que $A$ ilusão americana era o livro "que eu tantas vezes lhe disse que ia escrever [...]. Expus-lhe, porém, porvezes as linhas gerais e disse-lhe que desejava que alguém o fizesse". Nabuco condenou a intervenção dos Estados Unidos ao lado da "ditadura" deFloriano durante a Revolta da Armada de 1893 a 1894, uma tentativa de restaurar a monarquia no Brasil: "Agora se puseram sob a inscrição de Santo Monroe!... Acabam a guerra cedendo o Amazonas aos Estados Unidos em sinal de agradecimento e solidariedade americana. Com o México"10.
[8] Nabuco para Rio Branco, 31 de julho de 1890 , apud Bueno, Clodoaldo. "O Barão do Rio Branco e o projeto da América do Sul". In: Car$\operatorname{dim}$ Carlos Henrique e Almino, João (orgs.). Rio Branco, a América do Sul e a modernização do Brasil. Brasília: Funag, 2002, p.388; Diários, op. cit., vol. II, pp. 34-5, 67-8: 28 fev. 1891, 16 out. 1893 .

[9] Nabuco, Balmaceda, op. cit., pp. 215-16, 219 .

[10] Diários, op. cit., vol. II, p. 88: 5 dez. 1893; p. 81: 4 nov. 1893. Sobre o envolvimento dos Estados Unidos na revolta naval entre 1893 e 1894 , ver Topik, Steven C. Comércio e canonheiras. Brasil e os Estados Unidos na era dos impérios [1996]. São Paulo: Companhia das Letras, 2009, caps. 7 e 8; Smith, Joseph. Unequal giants: diplomatic relations between the United States and Brazil, 1889-1930. Pittsburgh, PA: University of Pittsburgh Press, 1991, pp.19-25. 
[11] Nabuco.A intervenção estrangeira durante a revolta. Rio de Janeiro: Leuzinger, 1896 , p. 260.

[12] Nabuco, Balmaceda, op. cit., pp. 220-1. Cf. Diários, op. cit., vol. II, pp. 409-410: 6 set. 1907 (Nabuco para Rui Barbosa).

[13] Diários, op. cit., vol. II, pp. 231: 15-16 jun. 1901 (Nabuco para Tobias Monteiro, 14 jun.1901); Nabuco, Cartas a amigos (Vol.I:1864-1898; Vol. II: 1899-1909). Org. Carolina Nabuco. In: Obras completas, vols. XIII e XIV. São Paulo: Instituto Progresso Editorial, 1949, vol. II, p. 140: 15 dez. 1902 (Nabuco para Tobias Monteiro).
Nabuco tornou-se - e permaneceu - extremamente preocupado com as ameaças à integridade territorial do Brasil. Desde o Congresso de Berlim em 1885 a Europa ingressara numa nova era do imperialismo, mais evidente na África, mas que, segundo Nabuco, também representava uma ameaça à América Latina. A soberania não europeia sobre os territórios não ocupados estava sendo cada vez mais desafiada. A soberania brasileira sobre a maior parte da região amazônica estava, por conseguinte, cada vez mais vulnerável.

Apesar de alguma preocupação quanto ao intervencionismo dos Estados Unidos - em seu livro sobre o envolvimento norte-americano na revolta naval de 1893-1894, A intervenção estrangeira (1896), advertia que a "intervenção [...] é sempre na história o modo por que primeiro se projeta sobre um estado independente a sombra do protetorado"11 - Nabuco acreditava que o imperialismo europeu, principalmente o inglês e o alemão, era uma ameaça maior ao Brasil e à América Espanhola do que o imperialismo estadunidense. Os Estados Unidos não buscavam colônias na América Latina, argumentava em Balmaceda, porque isso causaria "um profundo desequilíbrio em seu sistema do governo e uma incalculável deterioração de sua raça”. E a Doutrina Monroe era a melhor garantia de que não haveria nenhuma "recolonização europeia da América". "No fundo, o que é o Monroismo?", perguntava. "O Monroismo parecia ser a promessa feita à América pela União Americana de que a Europa não adquiriria mais uma palma de terra no Novo Mundo"12.

Em junho de 1901, de Londres, pediu ao seu amigo, o jornalista Tobias Monteiro, à época secretário do presidente Campos Sales, para informar ao presidente que ninguém era "mais monroísta do que eu [...] se não fosse o espantalho norte-americano [...] a Europa já estaria tratando a América do Sul como a China, a Ásia e a África". Em dezembro de 1902, chamou de "disgusting" (em inglês mesmo) as últimas edições de duas revistas publicadas em Londres, o Spectatore a Saturday Review: "Discute-se a partilha da América do Sul como se fosse a África. Parecem supor que o Brasil já pertence à esfera alemã"13. A experiência de Nabuco (e sua derrota final) na arbitragem internacional das fronteiras do Brasil com a Guiana Inglesa (1899-1904) só serviu para reforçar suas preocupações em relação às ameaças externas à conservação do "imenso todo chamado Brasil".

Em março de 1899, Nabuco encerrou seu período de "exílio interno" ao aceitar o convite do presidente Campos Sales para assumir a chefia de uma missão especial a Londres para elaborar e apresentar a posição do Brasil em sua disputa com a Grã-Bretanha sobre a Guiana Inglesa. No final de maio estava de volta à sua amada Londres, embora passaria, na prática, a maior parte dos doze meses seguintes em Paris. Com a morte repentina de seu amigo 
Arthur de Souza Corrêa, em março de 1900, Nabuco foi convidado a se tornar representante do Brasil em Londres, mas só viria a assumir efetivamente o cargo quase um ano depois. E mesmo então continuou a trabalhar sobretudo na questão da Guiana, em Paris e em Roma. O veredito do rei da Itália Vítor Emanuel III em favor da Grã-Bretanha, anunciado em 14 de junho de 1904, representou um tremendo choque para Nabuco. Foi "um quarto de hora terrível, o da leitura que o rei nos fez, ao embaixador inglês e a mim... vitória da Inglaterra... um desastre...", escreveu à sua esposa Evelina. A Inglaterra ganhou a maior parte do território disputado na bacia do rio Amazonas. "Não me hei de suicidar por a ter perdido...", anotou em seu diário, "mas o coração sangra-me, parece-me que sou eu o mutilado do pedaço que falta ao Brasil...". Nabuco lamentou amargamente que "um terço ou um metade do nosso país... todos os nossos sertões desconhecidos ou desocupados", tornou-se "um campo vastíssimo para o estrangeiro" 14 .

Menos de uma semana depois da decisão sobre a Guiana Inglesa, Nabuco recebeu um telegrama do barão do Rio Branco, que se tornara ministro das Relações Exteriores em dezembro de 1902, que ele descreveu a Evelina como "um terremoto"15. A legação brasileira em Washington seria elevada à condição de embaixada e ele foi convidado a ser o primeiro embaixador brasileiro nos Estados Unidos.

\section{III}

Às vésperas do século XX, grandes mudanças geopolíticas, econômicas e culturais estavam acontecendo no mundo: a emergência de uma nova ordem mundial e o surgimento de novas potências econômicas, navais e militares - a Alemanha na Europa, e os Estados Unidos nas Américas - desafiavam a hegemonia global britânica. As intenções e as ambições dos Estados Unidos foram claramente reveladas pela convocação da primeira Conferência Pan-Americana em Washington, em 1889-1890, pelo comentário do secretário de estado norte-americano Richard Olney durante a crise da Venezuela em 1895 ("Os Estados Unidos são praticamente soberanos neste continente e seu fiat tem força de lei para os sujeitos que estão confinados à sua interposição") e pela intervenção norte-americana na guerra de independência de Cuba da Espanha (1898), seguida pela anexação de Porto Rico e pelo estabelecimento de um protetorado sobre Cuba.

Dois anos depois de Rio Branco ter se tornado ministro das Relações Exteriores, o presidente Theodore Roosevelt incluiu, em sua mensagem anual ao Congresso (dezembro de 1904), o chamado corolário à Doutrina Monroe:
[14] Diários, op. cit., vol. II, p. 310: 14 jun. 1904 (Nabuco para Evelina); p. 323: 17 jun. 1904. Ver também cartas a Evelina e Alexandre Barbosa Lima, apud Costa, João Frank da. Joaquim Nabuco e a política exterior do Brasil. Rio de Janeiro: Record, 1968, p. 49.

[15] Diários, op. cit., vol. II, p. 324:19 jun. 1904 (Nabuco para Evelina). 
[16] Apud Bueno, op. cit., p.388: Rio Branco para Sousa Correia, 1896.

[17] Salvador de Mendonça comentou, em Situação internacional do Brasil (1913), que Rio Branco sempre mostrara ter talento para romper portas abertas: "Quando, pois, o barão do Rio Branco mandou Sr. Joaquim Nabuco descobrir a América do Norte ela já estava descoberta, medida e demarcada", apud Topik. "Remembering and forgetting: Joaquim Nabuco, Salvador de Mendonça and Brazilian-United States friendship during the First Republic". Madison: University of Wisconsin, 2009, p. 8 (inédito); ver também Smith, op. cit., p. 50. Sobre as relações do Brasil com os Estados Unidos sob Rio Branco, o trabalho clássico continua sendo Burns, E. Bradford. The unwritten alliance: Rio-Branco and Brazilian-American relations. Nova York: Columbia University Press, 1966

[18] Diários,op.cit.,vol.II,pp. 253:24 fev. 1902; Cartas a amigos, op. cit., vol. II, p.132: 7 set. 1902 (Nabuco para Rio Branco).
Uma transgressão crônica, ou uma impotência que resulte num afrouxamento generalizado dos laços da sociedade civilizada, pode requerer em última instância, na América Latina como em outros lugares, a intervenção de algum podercivilizado [...]. No Hemisfério Ocidental, os Estados Unidos podem ser forçados, ainda que de forma relutante, ao exercício de um poder de polícia internacional.

Na visão brasileira, existiam dois gigantes no hemisfério ocidental, sem dúvida desiguais: os Estados Unidos e o Brasil, ambos de proporções continentais; ambos com recursos naturais abundantes e alto potencial econômico; ambos "democracias" [sic]; e ambos, acima de tudo, distintos da América Latina (ou América Espanhola). Era inevitável que a hegemonia regional norte-americana substituísse a britânica. Os Estados Unidos ficariam responsáveis pelo estabelecimento (muito necessário) da ordem, da paz e da estabilidade no hemisfério. Ao contrário da maioria dos governos hispano-americanos, que reagiam com suspeita e desconfiança a esse novo interesse norte-americano no hemisfério, o governo brasileiro não criticou os Estados Unidos pela intervenção em Cuba em 1898 e aprovou o corolário de Roosevelt à Doutrina Monroe em 1904.

Interessava ao Brasil fortalecer os laços políticos com os Estados Unidos. (Economicamente, os Estados Unidos já eram o maior mercado para aquele que se havia tornado o principal produto de exportação do Brasil — o café -, mas respondiam por menos de 10\% das importações do país e tinham poucos investimentos no Brasil.) Em 1896, Rio Branco escreveu: "Eu prefiro que o Brasil estreite as suas relações com a Europa a vê-lo lançar-se nos braços dos Estados Unidos" ${ }^{16}$. Como ministro das Relações Exteriores, contudo, buscou dar continuidade à reorientação da política externa brasileira na direção dos Estados Unidos, que começou com Salvador de Mendonça, e convidou Nabuco para servir em Washington ${ }^{17}$.

Em fevereiro de 1902, Nabuco descreveu em seu diário o posto em Washington como "desde agora politicamente o mais importante de nossa diplomacia". Em setembro, declarou a Rio Branco: "Eu sou um forte monroísta... e por isso grande partidário da aproximação cada vez maior entre o Brasil e os Estados Unidos"18. Três anos depois, ao responder a uma carta de seu primo, o barão de Albuquerque, congratulando-o por sua indicação como embaixador, que fora então tornada pública, escreveu: "estamos nas vésperas de uma nova era"; "um sistema político do globo" estava substituindo "o antigo sistema europeu”, e para observá-lo "o observatório de Washington é... o mais importante de todos". Não obstante, ele hesitou em aceitar o posto. Amava Londres - e Paris. Ademais, sua saúde estava cada vez mais precária. Washington era "um duplo desterro porque se está longe do 
Brasil e da Europa", escreveu a seu amigo, o escritor e diplomata Graça Aranha. "Não tenho entusiasmo algum pela idéia de ir lá acabar a minha carreira." Ele preferia continuar servindo em Londres, Roma ou Paris, declarou a Rio Branco, mas no final só aceitou Washington por causa de um forte desejo de "cooperar na fundação da nossa política americana"19.

Mesmo antes de apresentar suas credenciais de embaixador brasileiro ao presidente Roosevelt em Washington, em 24 de maio de 1905 , Nabuco expressou a Evelina, privadamente, suas dúvidas pessoais: "Estou com medo de ter feito uma grande tolice aceitando este posto... uma grandíssima tolice". Em seguida queixava-se da vida em Washington: "Preços excessivos, clima intolerável ('Que terrível calor. Imagino que estou em um banho turco'), alimentação péssima e nenhuma adaptação possível, voilà mon bilan (balanço). Isto para ti somente". "Não faço plano algum de demorar-me neste país. Prefiro acabar em qualquer outro. Isto muito entre nós dois. Por isso não vás imaginando nenhuma longa residência." E conclui: "não vejo nada que eu posso fazer aqui" 20. Porém, "a aproximação entre as duas grandes Repúblicas do Norte e do Sul" logo se tornou uma "causa" à qual ele se dedicou inteiramente. Ela preencheu um "vazio" em sua "alma" que "aquela grande ideia [a abolição] tinha deixado", declarou, em um discurso proferido em um banquete em sua homenagem durante a Conferência Pan-americana realizada no Rio de Janeiro em julho de $1906^{21}$.

"Dois caminhos que lhe deparam", escreveu ao barão do Rio Branco em dezembro de 1905, "o americano e o outro, a que não sei como chamar, se de latino-americano, se de independente, se de solitário. Eu, pela minha parte, sou francamente monroísta". Nabuco considerava "natural" a ascendência dos Estados Unidos no continente americano. Tinha pouco entusiasmo com relação à América Espanhola que, com exceção da Argentina e do Chile, era, na visão dele, uma região ainda caracterizada pela anarquia, guerra civil e caudilhismo. Isso não queria dizer que ele fosse favorável às intervenções eàs ocupações norte-americanas. "O meu monroísmo é mais largo... Para mim o que quero é uma espécie de aliança tácita, subentendida, entre os nossos dois países". E em uma longa carta a José Carlos Rodrigues, o proprietário e editor do Jornal do Commercio: "a única proteção da América é o sea-power que só os Estados Unidos têm nela. Monroísmo é assim a afirmação da independência e integridade nacional pelo único sistema que as pode garantir. Quero inteligência que pareça aliança tácita"22. O livro de Eduardo Prado (que morrera em 1901), A ilusão americana, que havia se tornado a bíblia dos nacionalistas brasileiros hostis aos Estados Unidos (incluindo agora Salvador de Mendonça), e que uma vez Nabuco havia desejado terescrito, era agora, declarou a Graça Aranha, "um livrinho que nos faz muito mal, entretém no espírito público a desconfiança contra este país [os Estados Unidos], nosso único aliado possível"23.
[19] Cartas a amigos, op. cit., vol. II, p. 200: 5 jan. 1905 (Nabuco para o barão de Albuquerque); Diários, op. cit., vol. II, pp. 314: 23 nov. 1904; Diários, op. cit., vol. II, p. 335: 23 ago. 1905 (Nabuco para Rio Branco).

[2o] Diários, op.cit., vol.II, p.351,354: 20 maio, 19 jun., 21 jun., 24 jun. 1905.

[21] Gazeta de Notícias, 24 de julho de 1906, apud Costa, op. cit., p. 93. Sobre Nabuco em Washington, ver Pereira, Paulo José dos Reis. A politica externa da Primeira Republica e os Estados Unidos: a atuação de Joaquim Nabuco em Washington (1905-1910). São Paulo: Hucitec, 2006.

[22] Cartas a amigos, op. cit., vol. II, p. 238: 19 dez. 1905 (Nabuco para Rio Branco); 3 jan. 1906 (Nabuco para Rio Branco).In: Costa, op.cit., p. 245; Diários, op. cit., vol. II, pp. 346-7: 12 dez. 1905 (Nabuco para José Carlos Rodrigues).

[23] Cartas a amigos, op. cit., vol.II, p. 235:17 dez. 1905 (Nabuco para Graça Aranha). Posteriormente, Nabuco queixou-se a Rio Branco sobre um outro livro que criticava o imperialismo dos Estados Unidos, de autoria de Manoel Bomfim, presumivelmente A América Latina: males de orígem (1905). "Você pode avaliar o mal que essa desfigura de tudo que é nossa, feita por um 'educador' brasileiro', pode fazer à nossa reputação entre as classes ilustradas [deste] país". Cartas a amigos, op. cit., vol. II, p. 302: 18 jan. 1908 (Nabuco para Rio Branco). 
[24] Diários, op. cit., vol. II, p. 365: 11 jun. 1906; p. 359: 9 fev. 1906. Sobre Nabuco e o pan-americanismo, ver Andrade, Olimpio de Souza. [Joaquim Nabuco e o pan americanismo, 1950] Joaquim Nabuco e o Brasil na América. 2 ed. São Paulo: Editora Nacional, 1978; Dennison, Stephanie. Joaquim Nabuco, panamericanism and nation-building in the Brazilian belle-epoque. Berlim: Peter Lang, 2006.

[25] Diários, op. cit., vol. II, p. 346:12 dez. 1905 (Nabuco para José Carlos Rodrigues); Cartas a amigos, op. cit., vol. II, pp. 230, 235-6, 236-40: 2 dez. 1905 (Nabuco para o presidente Rodrígues Alves); 17 dez. 1905 (Nabuco para Graça Aranha); 19 dez. 1905 (Nabuco para Rio Branco); Diários, op. cit., vol. II, p. 347: 17 dez. 1905 (Nabuco para José Carlos Rodrigues); 3 jan. 1906 (Nabuco para Rio Branco), apud Smith, op. cit., p. 54 .
Desde o início, o Brasil era mais favorável à ideia do pan-americanismo do que as repúblicas hispano-americanas - que temiam,com razão, que o pan-americanismo fosse uma ferramenta utilizada para ratificar a hegemonia política eeconômica dos Estados Unidos eassegurar a futura exploração da região - , e deu apoio total aos Estados Unidos nas Conferências Pan-Americanas. Nabuco via o Brasil como o interlocutor entre os Estados Unidos e a América Espanhola/Latina. Em uma audiência com o presidente Roosevelt, declarou que queria que sua estada em Washington marcasse não apenas uma nova era nas relações Brasil-Estados Unidos, mas também nas relações entre os Estados Unidos e todas as nações do continente. "Eu muito concorri para fazer a América Latina adotar outra atitude para com os Estados Unidos", escreveu em seu diário. Mas anteriormente, em um jantar na embaixada mexicana, declarara a Elihu Root, o secretário de Estado norte-americano no segundo mandato presidencial de Roosevelt e de quem havia se tornado um grande amigo: "You can flirt with them all [os países da América Latina], but I hope you will only marryus [Vocês podem flertar com todos, mas espero que só venham a se casar conosco]"24.

Em novembro de 1905, em uma reunião do secretariado da União Internacional das Repúblicas Americanas, sob a presidência de Root, a Costa Rica, apoiada pelos Estados Unidos e pelo México, que sediaram as duas primeiras Conferências Pan-Americanas, propôs que a Terceira Conferência fosse realizada na América do Sul, em julho de 1906. E, a despeito da oposição da Venezuela e da Argentina, a Junta finalmente escolheu o Rio de Janeiro. Nabuco convenceu o próprio Root a comparecer à conferência do Rio, algo sem precedentes. Seria a primeira visita oficial ao exterior feita por um secretário de Estado norte-americano.

Nabuco estava determinado, conforme informou a José Carlos Rodrigues, "a tornar o Congresso um grande sucesso" e, o que era ainda mais importante, "a visita do Secretário de Estado um grande acontecimento". Considerava a visita de Root - e planejou reuniões dele com dois presidentes brasileiros (Rodrigues Alves, que estava prestes a deixar o cargo e com quem Nabuco se comunicava diretamente, e Afonso Pena, que em breve assumiria a presidência), bem como com seu colega Rio Branco - um evento de enorme significado político. Ficou frustrado com a aparente recusa de Rio Branco em conferir ao secretário "a importância que tem perante o mundo todo". A conferência "será um acontecimento mínimo para o mundo e minimíssimo para nós ao lado daquele [a visita de Root]"; "a presença dele é que éo acontecimento, não a dos delegados". Ele pressionou Rio Branco a tirar partido de "uma ocasião maior, única, de sua vida", "uma oportunidadeúnica... para lançarem as primeiras bases sólidas de uma entente que acredito destinada a se tornar um dia aliança" 25 . 
Como ministro das Relações Exteriores, Rio Branco era obrigado a ser mais flexível, mais pragmático, mais cauteloso do que seu embaixador em Washington. Ele tinha algumas preocupações sobre o corolário Roosevelt à Doutrina Monroee ao uso do Big Stick para consolidar a hegemonia norte-americana no hemisfério. Como explicou o diplomata e historiador Manuel de Oliveira Lima (e com conhecimento de causa, disse ele) em artigo que escreveu para o Jornal do Recife durante a Conferência do Rio:

[...] [o barão] não desejaria vero Brasil reduzido à condição passiva de satélite, imposta por uma dura necessidade política ou pela fatalidade geográfica [...] [para ele] a amizade americana não deve significar a subalternação brasileira, isto é, a abdicação da nossa personalidade internacional mediante a supressão, em homenagem aos Estados Unidos, dos nossos juizos e preferências ${ }^{26}$.

Rio Branco compreendia a importância da manutenção dos laços culturais do Brasil com a Europa, especialmente Portugal e França, e das relações comerciais e financeiras com a Grã-Bretanha. (A Grã-Bretanha continuou sendo o mais importante parceiro comercial do Brasil até a Primeira Guerra Mundial e seu principal parceiro financeiro até 1930.) Ademais, o homem que vinte anos antes havia descrito "essas repúblicas hispano-americanas" como "turbulentas", "imaginárias", e mesmo "ridículas" (e os "súditos de Gusmões Blancos e Porfírios Dias" como extremamente invejosos do Brasil) ${ }^{27}$, era agora mais simpático à América Espanhola em geral, e à Argentina e ao Chile em particular, os quais, reconhecia, haviam começado a fazer progressos econômicos e políticos significativos nos últimos anos. Por essa razão, ele estava ansioso em desenvolver relações mais próximas com as três grandes repúblicas da América do Sul.

A Terceira Conferência Pan-Americana - que trouxe Nabuco ao Brasil pela primeira vez em sete anos, como chefe da delegação brasileira - foi realizada entre 25 de julho e 27 de agosto de 1906 no Palácio Monroe, que foi construído para o evento, em boa parte inspirado no pavilhão brasileiro na Feira Mundial de St. Louis em 1903-1904 para comemorar o centenário da compra da Luisiana.AConferência produziu poucos resultados concretos. Como as duas anteriores, consistiu principalmente em um exercício para manter boas relações entre os estados americanos. Nabuco atuou no sentido de manter o antiamericanismo dos delegados hispano-americanos firmemente sob controle, mas ficou desapontado com o discurso proferido por Rio Branco na abertura da Conferência (ele preferiu enfatizar as raízes e os laços europeus da América Latina: "[a Europa] nos criou, ela nos ensinou"), bem como com a decisão de Root de visitar Buenos Aires e outras capitais sul-americanas após a Conferência.
[26] Jornal do Recife, 26 ago. 1906, apud Almeida, Paulo Roberto de. "O Barão do Rio Branco e Oliveira Lima: vidas paralelas, itinerários divergentes". In: Cardim e Almino (orgs.), op. cit., pp. 267-8. Oliveira Lima considerava os Estados Unidos "agressivamente imperialista", o corolário Roosevelt à Doutrina Monroe como uma séria ameaça à soberania latino-americana, e o pan-americanismo como uma tentativa de "latinizar o monroísmo" e promover a "hegemonia hemisférica". Ver Lima, Manuel de Oliveira. Pan-Americanismo (Monroe, Bolivar, Roosevelt). Rio de Janeiro: Garnier, 1907 (artigos originalmente publicados em O Diário de Pernambuco e O Estado de São Paulo 1903-1906). Foi por causa disso que Nabuco rompeu formalmente a amizade com seu conterrâneo pernambucano. Ver Cartas a amigo, op. cit., vol. I, p. 250: 30 mar. 1906 (Nabuco para Oliveira Lima). Em suas memórias, Oliveira Lima refere-se a Roosevelt e a Root como "dois fetiches norte-americanos" de Nabuco. Ele era contrário a entente ultra-cordiale Estados Unidos-Brasil de Nabuco. Ver Lima.Memórias, estas minhas reminiscências. Rio de Janeiro: José Olympio, 1937, pp. 212, 217. Ver também Silveira, Helder Gordim da. Joaquim Nabuco e Oliveira Lima: faces de uma paradigma ideológico da americanização nas relações internacionais do Brasil. Porto Alegre: Editora da PUC-RS, 2003.

[27] Rio Branco para barão Homem de Mello, 13 set. 1887, apud Bueno, op. cit., p.359. 
No período que se seguiu à Conferência do Rio, Nabuco continuou a acreditar que manter relações estreitas com os Estados Unidos era "a nossa única política externa possível". Ele advertiu Rui Barbosa que, na Segunda Conferência de Paz, realizada em Haia, em junho de 1907, a estreia do Brasil no cenário internacional, apoiara "as nações latino-americanas" contra os Estados Unidos na questão central da representação igualitária na Corte Internacional de Justiça — para não explorar o antiamericanismo sendo triunfalista, pois isso aumentaria o ressentimento e a má vontade dos Estados Unidos para com o Brasil. "Entre a Europa e a América", escreveu ao seu amigo, o ex-governador de Pernambuco, Alexandre Barbosa Lima,

[...] por bem ou por mal, não há escolha para nenhuma nação da América Latina... [E] naAmérica (quando não fosse por outra causa, pela exceção da lingua, que nos isola do resto da Ibero-América, como separa Portugal da Espanha), não podemoshesitarentre os Estados Unidose a América Espanhola.

A aliança não escrita com os Estados Unidos (e a segurança proporcionada pela Doutrina Monroe) continuava, na sua opinião, sendo "o alfa e o ômega da nossa política externa". "Estou dedicando o resto da minha vida ativa à aproximação íntima dos dois países... as principais repúblicas do hemisfério", disse ele a Rio Branco. Considerava a "aliança sul-americana", a liga ABC [Argentina, Brasil, Chile], um "absurdo", que teria "consequências desastrosas". Ele só tinha aceitado ir para Washington "para fazer nele política de aproximação americana e para ela a nossa aliança com a Argentina e o Chile seria o dobre fúnebre". "Ele [Rio Branco] confia na Alemanha, na França, na Itália, no Chile, na Argentina, não sei em quem mais", comentou com seu cunhado Hilário de Gouvêa, "e eu só confio nos Estados Unidos", acrescentando que estava "cansado e desiludido da minha missão aqui

[28] Diários, op. cit., vol. II, pp. 409-10: 6 set.1907 (Nabuco para Rui Barbosa); Cartas a amigos, op. cit., vol. II, p. 277: 7 jul. 1907 (Nabuco para Alexandre Barbosa Lima); p. 300: 18 jan. 1908 (Nabuco para Rio Branco); p.330: 19 jan. 1909 (Nabuco para Hilário de Gouvêa).

[29] Diários, op.cit.,vol.II, pp.431-32: 8 jun. 1908 (Nabuco para José Carlos Rodrigues). [em Washington]"28.

Quanto ao pan-americanismo, Nabuco estava satisfeito com o progresso que fizera na melhoria das relações dos Estados Unidos com as repúblicas hispano-americanas. Apesar da persistente indiferença dos Estados Unidos em relação à América Latina e do persistente medo e desconfiança dos hispano-americanos em relação aos Estados Unidos (e, no caso da Argentina e de seu ministro das Relações Exteriores Estanislao Zeballos, também ao Brasil), o Bureau, o secretariado da União Internacional dos Estados Americanos, que fora "um foco de conspiração e má vontade contra os Estados Unidos" quando ele chegou, tornou-se, argumentava, "um campo de liça em que os combatentes lutam pelo primeiro lugar na amizade e confiança americana"29. 
Porém, ele continuava a terdúvidas sobre as repúblicas hispano-americanas ea União dos Estados Americanos. "Uma coisaéo Brasil esforçar-se para entrar para o círculo diretor da humanidade (do mundo civilizado)... outraé reclamar para Honduras, Haiti e Panamá,etc. a mesma situação que tiver a Inglaterra, a Alemanha, os Estados Unidos, etc." No Bureau todas as repúblicas americanas eram iguais. Assim, o voto da Nicarágua equivalia ao dos Estados Unidos, o do Haiti ao do Brasil. "O Brasilvale menos do que duas quaisquer repúblicas da América Central". Além do mais, enquanto a América Inglesa (os Estados Unidos) tinham um voto (Canadá não era membro) e a América Portuguesa (o Brasil), que por um milagre da história permanecera unida, um voto, a América Espanhola, em virtude do seu "fracasso histórico" e da fragmentação, tinha dezoito votos! E as "republiquetas" de fala espanhola "têm tendência natural de formar uma unidade com perto de vinte votos contra o nosso voto único"30. O Brasil não podia reivindicar nenhum "lugar privilegiado" ao lado dos Estados Unidos.

À exceção de uma visita oficial a Havana, como embaixador especial, em janeiro-fevereiro de 1909 para assistir à restauração do governo nacional de Cuba, Nabuco passou seus dois últimos anos nos Estados Unidos preparando a quarta Conferência Internacional dos Estados Americanos, que seria realizada em Buenos Aires, em julho de 1910. Como chefe da delegação brasileira, planejou audaciosamente apresentar uma moção em favor da Doutrina Monroe (sem muita expectativa de que ela seria apoiada pelas repúblicas hispano-americanas).Também pronunciou uma série de conferências em universidades norte-americanas - Yale, Chicago, Vassar, Cornell e Wisconsin — sobre Camões e Os Lusíadas, o espírito da nacionalidade na história do Brasil, as duas Américas (os Estados Unidos e a América Latina) e a civilização americana (isto é, dos Estados Unidos) ${ }^{31}$.

EmMinha formação (1900) o julgamento de Nabuco sobre a civilização norte-americana foi negativo (como ao final da sua estada nos Estados Unidos em 1877):

Tudo isso sugere grande inovações futuras, mas não existe ainda o menor sinal de que a elaboração do destino humano ou a revelação superiorfeita ao homem tenha um dia que passar para os Estados Unidos. A sua missão na História é ainda a mais absoluta incógnita. Se ele desaparecesse de repente, não se pode dizer o que é que a humanidade perderia de essencial, que raio se apagaria do espírito humano; não é ainda como se tivesse desaparecido a França, a Alemanha, a Inglaterra, a Itália, a Espanha32.

(Curiosamente, Portugal não estava na lista.) Uma década mais tarde, Nabuco tornou-se um grande admirador dos Estados Unidos e da civilização norte-americana, que ele via, essencialmente, como uma extensão da civilização europeia, especialmente da inglesa.
[30] Cartas a amigos, op. cit., vol. II, pp. 286, 290, 294: $1^{\circ}$ set. 1907 (Nabuco para Hilário de Gouvêa); 2 set. 1907 (Nabuco para Graça Aranha); 20 out. 1907 (Nabuco para Rio Branco); 22 out. 1907 (Nabuco para Rui Barbosa).

[31] Nabuco. Discursos e conferências nos Estados Unidos. Trad. Artur Bomilcar. Rio de Janeiro: B. Aguila, 1911; ibidem, Camões e assuntos americanos: seis conferências em universidades americanas. Trad. Carolina Nabuco. São Paulo: Editora Nacional, 1940.

[32] Nabuco, Minha formação, op. cit., p.159. 
[33] A palestra de Wisconsin (23 de junho de 1909) foi publicada na American Historical Review (outubro de 1909) e em português ("A contribuição da América à civilização") na primeira edição da Revista Americana, criada em 1909 pelo Itamaraty com o objetivo de aprofundar as trocas políticas e culturais entre o Brasil, a América Latina e os Estados Unidos.

Recebido para publicação em 29 de agosto de 2010 .

\section{NOVOS ESTUDOS}

CEBRAP

88 , novembro 2010

pp. $73-87$
Em junho de 1909, na Universidade de Wisconsin, em Madison, em sua última palestra, intitulada "The share of America in civilization" - que foi lida em seu nome porque nessa ocasião estava muito doente para viajar (morreu seis meses mais tarde) -, Nabuco declarou que embora muito provavelmente o destino da humanidade no fim fosse o mesmo, se a América nunca tivesse aparecido acima da água, sem ela, muito do que já fora acrescentado à civilização não existiria. Ele mencionou não somente o bem-estar material, mas também a individualidade, a democracia, a educação, a imigração e "equality of social conditions [igualdade das condições sociais]" (nessa ocasião já tinha lido Tocqueville!). Entretanto, não havia, em sua opinião, nenhuma evidência de que a hegemonia intelectual estava passando da Europa para a América. "A Europa não começou a decair", declarou. "Por muitos séculos, Europa e América liderarão juntas". "Falando da América eu tenho o tempo todo tomado a parte pelo todo e falado apenas deste país [os Estados Unidos]. É um pouco prematuro falar da parte atribuída na história à América Latina" 33 . Ele não deixou claro se estava incluindo o Brasil como parte da América Latina em seu pensamento ao fim da sua vida.

Cem anos mais tarde, no centenário de sua morte, quando a política externa brasileira confere prioridade as relações Sul-Sul e as relações do Brasil com os seus vizinhos na América Latina eespecialmente na América do Sul, é importante lembrar a centralidade das relações do Brasil com a Europa e com os Estados Unidos no pensamento do Joaquim Nabuco.

LESLIE BeTHELl é professor emérito de História da América Latina na Universidade de Londres, fellow emérito do St. Antony's College, Universidade de Oxford, e pesquisador associado do Centro de Pesquisa e Documentação de História Contemporânea do Brasil (CPDOC) da Fundação Getulio Vargas, Rio de Janeiro. É editor de Cambridge History of LatinAmerica, 1984-2008, 12 vols. 